\section{Analysis of the Indigenous and Pathogenic Microbiota in Bone Sequestration due to Osteonecrosis of the jaws by Bisphosphonates (MRONJ)}

\section{Picardo Silvana $N^{1 *}$, Rodriguez Genta Sergio $A^{1}$, Mosca Christian $^{2}$ and Rey Eduardo $A^{3}$}

${ }^{1}$ Assistant Teacherin Oral and Maxillofacial Surgery II, School of Dentistry, University of Buenos Aires, Argentina

${ }^{2}$ Dentist Specialist in Maxillofacial Surgery, Phd in Public Health, Assistant Professor in the Microbiology and Immunology Department, Kennedy University Buenos Aires, Argentina

${ }^{3}$ President of the National Academy of Dentistry, Consultant to the National Academy of Medicine, Former Professor of Oral and Maxillofacial Surgery, School of Dentistry, University of Buenos Aires, Argentina

\begin{abstract}
The American Surgery of Bone Mineral Research (ASBMR) defined MRONJ as "necrotic bone area exposed to the oral environment with more than eight weeks of permanence, in the presence of chronic treatment with BPs, in the absence of radiation therapy to the head and neck in 2007.

This publication analyzes the colonization of the exposed bone, and the preventive measures to take into account to avoid a spread of the infection by continuity or contiguity to neighboring anatomical spaces, complicating the clinical picture of MRONJ. The main colonizer is Actinomyces spp., but there are other oral microorganisms (including Candida spp.) that can be favored by the metabolic conditions, mechanical retention and microbial succession to lodge in necrotic bone.
\end{abstract}

*Corresponding author: Picardo Silvana N, Assistant Teacherin Oral and Maxillofacial Surgery II, School of Dentistry, University of Buenos Aires, Argentina, Email: silvana_picardo@hotmail.com

Citation: Silvana NP, Sergio ARG, Christian M, Eduardo AR (2020) Analysis of the Indigenous and Pathogenic Microbiota in Bone Sequestration due to Osteonecrosis of the jaws by Bisphosphonates (MRONJ). J Dent Oral Health Cosmesis 5: 016 .

Received: September 19, 2020; Accepted: September 25, 2020; Published: October 01, 2020

Copyright: ( 2020 Silvana NP, et al. This is an open-access article distributed under the terms of the Creative Commons Attribution License, which permits unrestricted use, distribution, and reproduction in any medium, provided the original author and source are credited.
Keywords: Antiresorptives drugs (AR); Anti-angiogenic drugs; Medication Related Osteonecrosis of the Jaw (MRONJ); Microbiology

\section{Introduction}

Bisphosphonates (BP) are a pharmacological class of synthetic inorganic pyrophosphate analogs that have an affinity for calcium. They are used in the treatment of various benign and malignant metabolic conditions, such as Paget's disease; multiple myeloma; and metastases from distant sites such as breast, thyroid, prostate, and lung. The oral form of BP is indicated in the treatment of osteoporosis, fibrous dysplasia and, more recently, imperfect osteogenesis in the pediatric population.

The American Surgery of Bone Mineral Research (ASBMR) defined MRONJ as "necrotic bone area exposed to the oral environment with more than eight weeks of permanence, in the presence of chronic treatment with BPs, in the absence of radiation therapy to the head and neck"in 2007 [1].

American Association of Oral and Maxillofacial Surgeons (AAOMS) in 2014 divided the MRONJ into 4 stages from 0 to 3 according to the clinical and radiological aspect of the osteonecrotic lesion: stage 0: Osteonecrotic lesion without sign-pathognomonic 1: osteonecrotic lesion with clinical signs and but no clinical symptoms; Stage 2: Osteonecrotic lesion with sign and clinical symptoms; Stage 3: Osteonecrotic lesion with signs and symptoms that involve other structures such as: pathological fractures, anesthesia of the lower dental nerve, oral-nasal communication, oral-sinus communication, skin fistulas [2].

Bone exposed for at least 8 weeks in duration with or without pain it can signify the diagnosis of MRONJ. In studies of exposed bone, colonization of Actinomyces spp. without knowing if they play a critical role or is a secondary infection in the pathogenesis of MRONJ. Actinomyces are part of the normal microbiota of the oral cavity, however, it is difficult to determine whether it represents microbial colonization in hard and soft tissues or is a true infection, being the clinical experience, that this pathogen Microbial is an opportunistic bacterium directly involved in the pathology of the hard and soft tissues of the maxillofacial region and oral cavity in the MRONJ patient [3-5].

Ruggiero, et al. evidenced any cases in which the diagnosis of Actinomyces was established, bone exposure was not always observed, which corresponds to incipient stages in the exposure document of the American Association of Oral and Maxillofacial Surgeons [6]. A review published cases identified multiple bacterial species in patients with MRONJ, the main one being Actinomyces [4,7], but other microbial pathogens are also evident, such as: Streptococcus, Staphylococcus, Treponemes, Bacteroides, Actinobacillus, Moraxella and Eikenellacorrodens $[5,8]$. It is believed that these microorganisms 
exert a synergistic effect on the pathogenesis of the disease, secreting bacterial enzymes, such as collagenases and hyaluronidases, which destroy tissues and promote the extension of the lesion to other areas of the head and neck.

It is known that the microbiological culture in an anaerobic medium will be carried out when empirical antibiotic therapy is not effective, a decision made together with the treating Antibiograms are generally not applicable to determine the correct treatment of MRONJ since the bacterial flora found corresponds to the usual pathogenic oral microbiota: Phorphyromona gingivalis and Aggregatibacter actinomycetemcomitans [9]. Therefore, based on the scientific evidence, it is currently not known whether infection of the jaws and overlying soft tissues is a primary or secondary event in MRONJ [911]. Management of MRONJ remains a significant clinical challenge. The objective of this article is to explore current theories about the importance of infection in the development of this devastating pathology.

\section{Discussion}

There is clinical evidence that Actinomyces may play a fundamental role in the pathogenesis of MRONJ associated with bisphosphonates: antiresorptive and antiangiogenic. Identification and a prolonged course of oral antimicrobial therapy can lead to complete resolution of this actinomycotic osteonecrosis. Failure to identify Actinomyces spp. and initiate antibiotic treatment could be responsible in many cases for making treatment difficult and refractory [12-18]. The detection of Actinomyces spp. in $89 \%$ of bone samples by histology is remarkable, but there may still be a significant underestimation of the true frequency of MRONJ associated with this infection [19]. Some authors recommend beta-lactam agents since they have a high therapeutic index that allows the safe administration of high doses of drugs and high levels of therapeutic drugs are reached in serum, tissues, bile and synovial fluid.

Steininger, et al. stated that Actinomyces spp. isolates are universally susceptible to beta-lactam antimicrobial agents [20] and that treatment without a beta-lactamase inhibitor also significantly reduces the rate of gastrointestinal adverse events such as abdominal discomfort or diarrhea from any cause, including Clostridium difficile enterocolitis. Consequently, they recommend for the treatment of actinomycosis in concordance with others the use of beta-lactam antimicrobial agents in high daily doses before the final surgical treatment of MRONJ.

For patients with a penicillin allergy, tetracyclines are a good alternative for oral therapy, especially in milder presentations of the disease. In severe infections, carbapenems or the new compound tetracyclines may be appropriate therapeutic options [19-21].

Ivaniushko, et al. have identified 15 species of microorganisms demonstrating an important role of oral cavity pathogens in the development of osteonecrosis of the facial bones. Enterobacteriaceae were identified; Streptococcus spp; Fusobacterium spp; Staphylococcus spp; Prevotella; Porphyromonas; Megasphera; Veilonella; Dialister; Corynebacterium; Mobiluncus; Leptotrichia; Sneatia; Lachnobacterium; Clostridium; Peptostreptococcus spp; Eubacterium spp; Candida spp in maxillary osteonecrosis of patients [22]. It is believed that the exposure of bone to the oral environment generates the appropriate conditions for the microbial colonization of all these species, and that they act by aggravating the clinical and exacerbate symptoms in the area.

Based on comparison above, other parts of the body, bone can be easily colonized by the abundant microbiota of bacterias and yeasts in the oral cavity (including periodontal pockets and periapical abscesses). Various studies confirm that the use of systemic antibiotics cannot restrict the colonization of bacteria after the initiation of MRONJ [23]. There is no consensus on how is the best way patient's be prescribed antiresorptive medication. Our protocol is exhaustive with the use of antiseptics to control the oral microbiota, so that it does not colonize bone sequestration and diffuse other spaces due to contiguity or continuity. Studies have demonstrated that a onetime use of chlorine dioxide containing mouth rinse significantly improves mouth odor pleasantness, reduces mouth odor intensity, and reduces volatile sulfur compound concentrations in mouth air for at least 8 hours after use [24].

Chlorhexidine is widely used in mouthwash solutions, but is also found in dental gels and toothpaste. Chlorhexidine in mouthwash solutions binds to oral mucosal surfaces via electrostatic forces, inhibits dental plaque formation and exerts a bacteriostatic action that persists for several hours [25]. Povidone-iodine mouthwash is the only approved mouthwash for pre-procedural rinsing in dental practice as antibacterial, antiviral, and antifungal effects according to the available literature [26]. At last, Cetylpyridinium chloride is the most common and effective mouthwashes used in dental practice [27].

It is essential patients with MRONJ be treated in an interdisciplinary fashion. Stomatognathic system should be examined preventatively prior to the initiation of BP, DS or anti angiogenic drugs treatment in order to avoid pathological buccal manifestations, following the same healthcare clinical protocols are used for patients who receive head and neck radiotherapy. Additionally, patients should be informed of the precautions to be taken, including regular dental appointments for oral health assessment. The risk of developing MRONJ should be evaluated according to the type of AR or anti angiogenic drugs which are indicated depends on treatment duration. [27, 28].

\section{Conclusions}

MRONJ Etiopathogenesis has not been fully elucidated, although there are many theories that attempt to explain it. Some authors point in infection as the main cause and not just a secondary event to bone exposure $[29,30]$. Others authors publicated that bone impregnated with $\mathrm{AR}$ is less resistant to bacterial infection and there is colonization by the normal microbiota as an ideal incubator for periapical periodontal microorganisms, which stimulate chronic inflammation [31]. Also other authors, who suggest an electrostatic interaction between nitrogen-containing bisphosphonates and Gram-positive bacteria, which would favor bone infection by these microorganisms [32].

The main colonizer is Actinomyces spp, but other oral microorganisms (including Candida spp) can be favored by the metabolic conditions, mechanical retention and microbial succession to lodge in necrotic bone. Therefore, based on our protocols, the use of antiseptics is highly recommended to control colonization with microorganisms avoid oral microbiota. Recommending the use of Chlorhexidine on a rotating basis; Povidone Iodine; Cetylpyridinium 
Citation: Silvana NP, Sergio ARG, Christian M, Eduardo AR (2020) Analysis of the Indigenous and Pathogenic Microbiota in Bone Sequestration due to Osteonecrosis of the jaws by Bisphosphonates (MRONJ). J Dent Oral Health Cosmesis 5: 016.

Chloride and Rifamycin to avoid generating microbial resistance to them, Antiseptic washes were started with Chlorhexidine $0.12 \%$, Povidone Iodo $10 \%$, Rifamycin $0.05 \%$ and Cetylpyridinium Chloride $0.5 \%$ alternating them fifteen days each other, in order to produce the reflux of the inflammatory content, opportunely accompanied by antibiotic therapy: in the first instance amoxicillin 500mg with clavulanic acid $125 \mathrm{mg}$ every 8 hours, in case of a lack in the recovery response at 72 hours, metronidazole $500 \mathrm{mg}$ is added. In severe MRONJ situations we prefer to use ciprofloxacin $500 \mathrm{mg}$ every 12 hours for 7 days [27]. Prophylactic antibiotic is not necessary to clinical attention depend on MRONJ so, patients with MRONJ have no risk of bacterial Endocarditis, except patients like oncology comorbidity requires $[28,33,34]$.

\section{References}

1. Khan AA, Morrison A, Hanley DA, Felsenberg D, McCauley LK, et al. (2015) Diagnosis and management of osteonecrosis of the jaw: A systematic review and international consensus. J Bone Miner Res 30: 3-23.

2. Ruggiero SL, Dodson TB, Fantasia J, Goodday R, Aghaloo T, et al. (2014) American Association of Oral and Maxillofacial Surgeons position paper on medication-related osteonecrosis of the jaw--2014 update. J Oral Maxillofac Surg 72: 1938-1956.

3. De Ceulaer J, Tacconelli E, Vandecasteele SJ (2014) Actinomyces osteomyelitis in bisphosphonate-related osteonecrosis ofthe jaw (BRONJ): Themissing link?. Eur J Clin Microbiol Infect Dis 33: 1873-1880.

4. Naik NH, Russo TA (2009) Bisphosphonate-related osteonecrosis of the jaw: The role of actinomyces. Clin Infect Dis 49: 1729-1732.

5. Kaplan I, Anavi K, Anavi Y, Calderon S, Schwartz-Arad D, et al. (2009) The clinical spectrum of Actinomyces- associated lesions of the oral mucosa and jawbones: Correlations with histomorphometric analysis. Oral Surg Oral Med Oral Pathol Oral Radiol Endod 108: 738-746.

6. Ruggiero SL, Dodson TB, Assael LA, Landesberg R, Marx RE, et al (2009) American Association of Oral and Maxillofacial Surgeons Position Paper on Bisphosphonate-Related Osteonecrosis of the Jaws-2009 Update. J Oral Maxillofac Surg 67: 2-12.

7. Lee CYS, David T, Nishime M (2007) Use of platelet-rich plasma in the management of oral bisphosphonate-associated osteonecrosis of the jaw: A report of 2 cases. J Oral Implantol 33: 371-382.

8. Thumbigere-Math V, Sabino MA, Gopalakrishnan R, Huckabay S, Dudek $\mathrm{AZ}$, et al. (2009) Bisphosphonate-related osteonecrosis of the jaw: Clinical features, risk factors, management, and treatment outcomes of 26 patients. J Oral Maxillofac Surg 67: 1904-1913.

9. Sedghizadeh PP, Kumar SK, Gorur A, Schaudinn C, Shuler CF, et al (2008) Identification of microbial biofilms in osteonecrosis of the jaws secondary to bisphosphonate therapy. J Oral Maxillofac Surg 66: 767-775.

10. Mawardi H, Treister N, Richardson P, Anderson K, Munshi N, et al. (2009) Sinus tracts-An early sign of bisphosphonate-associated osteonecrosis of the jaws? J Oral Maxillofac Surg 67: 593-601.

11. Lazarovici TS, Yahalom R, Taicher S, Elad S, Hardan I, et al. (2009) Bisphosphonate-related osteonecrosis of the jaws: A single center study of 101 patients. J Oral Maxillofac Surg 67: 850-855.

12. Curi MM, Dib LL, Kowalski LP, Landman G, Mangini C (2000) Opportunistic actinomycosis in osteoradionecrosis of the jaws in patients affected by head and neck cancer: Incidence and clinical significance. Oncol oral 36: 294-299.
13. Hansen T, Wagner W, Kirkpatrick CJ, Kunkel M (2006) Osteoradionecrosis of the infected jaw: A follow-up study suggests a deterioration in the outcome of patients with Actinomyces-positive bone biopsies. Int J Oral Maxillofac Surg 35: 1001-1004.

14. Gaffney RJ, Walsh MA (1993) Cervicofacial actinomycosis: An unusual case of submandibular swelling. J Laryngol Otol 107: 1169-1170.

15. Stanton DC, Balasanian E (2009) Result of surgical treatment of bisphosphonate-related osteonecrosis of the jaw: Review of 33 surgical cases. J Oral Maxillofac Surg 67: 943-950.

16. Brooks GF, Butel JS, Morse SA (2001) Gram positive non-spore-forming bacilli: Corynebacterium, propionibacterium, listeria, erysipelothrix, actinomycetes, and related pathogens. En: Foltin J, Ransom J, Lebowitz H, Holton B, eds. Microbiologíamédica de Jawetz, Melnick \& Adelberg (22ndedn). Nueva York, NY: McGraw Hill Co,194-196.

17. Nagler R, Peled M, Laufer D (1997) Cervicofacial actinomycosis: A diagnostic challenge. Oral Surg Oral Med Oral Pathol Oral Radiol Endod 83: 652-656.

18. Russo TA (2010) Agents of Actinomycosis. En: Mandell GL, Bennett JE, Dolin R, eds. Mandell Douglas Bennett's Principles and Practice of Infectious Diseases (7thedn). Churchill Livingstone, London, United Kingdom.

19. Russmueller G, Seemann R, Weiss K, Stadler V, Speiss M, et al. (2016) The association of medication-related osteonecrosis of the jaw with Actinomyces spp. infection. Sci Rep 17: 31604.

20. Steininger C, Willinger B (2016) Resistance patterns in clinical isolates of pathogenic Actinomyces species. J Antimicrob Chemother 71: 422-427.

21. Martin MV (1985) Antibiotic treatment of cervicofacial actinomycosis for penicillin-allergic patients: A clinical and in vitro study. Br J Oral MaxillofacSurg 23: 428-434.

22. Ivaniushko TP, Poliakov KA, Medvedev IA, Shamanaev SV, Trofimov DI, et al. (2016) Conditionally pathogenic microorganisms in patients with bisphosphonate jaw osteonecrosis. Stomatologiia (Mosk) 95: 44-48.

23. Pushalkar S, Li X, Kurago Z, Ramanathapuram LV, Matsumura S, et al. (2014) Oral microbiota and host innate immune response in bisphosphonate-related osteonecrosis of the jaw. Int J Oral Sci 6: 219-226.

24. Frascella J, Gilbert RD, Fernandez P, Hendler J (2000) Efficacy of a chlorine dioxide-containing mouthrinse in oral malodor. Compend Contin Educ Dent 21: 241-256.

25. Lim KS, Kam PC (2008) Chlorhexidine--pharmacology and clinical applications. Anaesth Intensive Care 36: 502-512.

26. Farzan A, Firoozi P (2020) Common Mouthwashes for Pre-Procedural Rinsing in Dental Practice: Wich One Is Appropriate for Eliminating Coronaviruses? A Mini Literature Review. Regen Reconstr Restor 5: 2.

27. Picardo SN, Rey EA (2017) Clinical Healthcare Protocol for Bisphosphonate Related Osteonecrosis of the jaw. Int J Dent Oral Heal 3: 42-44.

28. Nishimura RA, Otto CM, Bonow RO, Carabello BA, Erwin III JP, et al. (2017) 2017 AHA/ACC Focused Update of the 2014 AHA/ACC Guideline for the Management of Patients With Valvular Heart Disease: A Report of the American College of Cardiology/American Heart Association Task Force on Clinical Practice Guidelines. Circulation 135: 1159-1195.

29. Scoletta M, Arduino PG, Dalmasso P, Broccoletti R, Mozzati M (2010) Treatment outcomes in patients with bisphosphonate-related osteonecrosis of the jaws: A prospective study. Oral Surg Oral Med Oral Pathol Oral RadiolEndod 110: 46-53.

30. Abughazaleh K, Kawar N (2011) Osteonecrosis of the jaws: what the physician needs to know: practical considerations. Dis Mon 57: 231-41. 
Citation: Silvana NP, Sergio ARG, Christian M, Eduardo AR (2020) Analysis of the Indigenous and Pathogenic Microbiota in Bone Sequestration due to Osteonecrosis of the jaws by Bisphosphonates (MRONJ). J Dent Oral Health Cosmesis 5: 016.

- Page 4 of 5 •

31. Wei X, Pushalkar S, Estilo C, Wong C, Farooki A, et al. (2012) Molecular profiling of oral microbiota in jawbone samples of bisphosphonate-related osteonecrosis of the jaw. Oral Dis 18: 602-612.

32. Kos M, Luczak K (2009) Bisphosphonates promote jaw osteonecrosis through facilitating bacterial colonization. Biosci Hypotheses 2: 34-36.

33. Limones A, Sáez-Alcaide LM, Díaz-Parreñp SA, Helm A, Bornstein M, et al. (2020) Medication-related osteonecrosis of the jaws (MRONJ) in cancer patients treated with denosumab Vs zoledronic acid: A systematic review and meta-analysis. Med Oral Patol Cir Bucal 25: 326-333.
34. Albanese M, Zotti F, Capocasale G, Bonetti S, Lonardi F, et al. (2020) Conservative non-surgical management in medication related osteonecrosis of the jaw: A retrospective study. ClinExp Dent Res 10: 1002. 


\section{di \\ meramo}

Advances In Industrial Biotechnology | ISSN: 2639-5665

Advances In Microbiology Research | ISSN: 2689-694X

Archives Of Surgery And Surgical Education | ISSN: 2689-3126

Archives Of Urology

Archives Of Zoological Studies | ISSN: 2640-7779

Current Trends Medical And Biological Engineering

International Journal Of Case Reports And Therapeutic Studies | ISSN: 2689-310X

Journal Of Addiction \& Addictive Disorders | ISSN: 2578-7276

Journal Of Agronomy \& Agricultural Science | ISSN: 2689-8292

Journal Of AIDS Clinical Research \& STDs | ISSN: 2572-7370

Journal Of Alcoholism Drug Abuse \& Substance Dependence | ISSN: 2572-9594

Journal Of Allergy Disorders \& Therapy | ISSN: 2470-749X

Journal Of Alternative Complementary \& Integrative Medicine | ISSN: 2470-7562

Journal Of Alzheimers \& Neurodegenerative Diseases | ISSN: 2572-9608

Journal Of Anesthesia \& Clinical Care | ISSN: 2378-8879

Journal Of Angiology \& Vascular Surgery | ISSN: 2572-7397

Journal Of Animal Research \& Veterinary Science | ISSN: 2639-3751

Journal Of Aquaculture \& Fisheries | ISSN: 2576-5523

Journal Of Atmospheric \& Earth Sciences | ISSN: 2689-8780

Journal Of Biotech Research \& Biochemistry

Journal Of Brain \& Neuroscience Research

Journal Of Cancer Biology \& Treatment | ISSN: 2470-7546

Journal Of Cardiology Study \& Research | ISSN: 2640-768X

Journal Of Cell Biology \& Cell Metabolism | ISSN: 2381-1943

Journal Of Clinical Dermatology \& Therapy | ISSN: 2378-8771

Journal Of Clinical Immunology \& Immunotherapy | ISSN: 2378-8844

Journal Of Clinical Studies \& Medical Case Reports | ISSN: 2378-8801

Journal Of Community Medicine \& Public Health Care | ISSN: 2381-1978

Journal Of Cytology \& Tissue Biology | ISSN: 2378-9107

Journal Of Dairy Research \& Technology | ISSN: 2688-9315

Journal Of Dentistry Oral Health \& Cosmesis | ISSN: 2473-6783

Journal Of Diabetes \& Metabolic Disorders | ISSN: 2381-201X

Journal Of Emergency Medicine Trauma \& Surgical Care | ISSN: 2378-8798

Journal Of Environmental Science Current Research | ISSN: 2643-5020

Journal Of Food Science \& Nutrition | ISSN: 2470-1076

Journal Of Forensic Legal \& Investigative Sciences | ISSN: 2473-733X

Journal Of Gastroenterology \& Hepatology Research | ISSN: 2574-2566
Journal Of Genetics \& Genomic Sciences | ISSN: 2574-2485

Journal Of Gerontology \& Geriatric Medicine | ISSN: 2381-8662

Journal Of Hematology Blood Transfusion \& Disorders | ISSN: 2572-2999

Journal Of Hospice \& Palliative Medical Care

Journal Of Human Endocrinology | ISSN: 2572-9640

Journal Of Infectious \& Non Infectious Diseases | ISSN: 2381-8654

Journal Of Internal Medicine \& Primary Healthcare | ISSN: 2574-2493

Journal Of Light \& Laser Current Trends

Journal Of Medicine Study \& Research | ISSN: 2639-5657

Journal Of Modern Chemical Sciences

Journal Of Nanotechnology Nanomedicine \& Nanobiotechnology | ISSN: 2381-2044

Journal Of Neonatology \& Clinical Pediatrics | ISSN: 2378-878X

Journal Of Nephrology \& Renal Therapy | ISSN: 2473-7313

Journal Of Non Invasive Vascular Investigation | ISSN: 2572-7400

Journal Of Nuclear Medicine Radiology \& Radiation Therapy | ISSN: 2572-7419

Journal Of Obesity \& Weight Loss | ISSN: 2473-7372

Journal Of Ophthalmology \& Clinical Research | ISSN: 2378-8887

Journal Of Orthopedic Research \& Physiotherapy | ISSN: 2381-2052

Journal Of Otolaryngology Head \& Neck Surgery | ISSN: 2573-010X

Journal Of Pathology Clinical \& Medical Research

Journal Of Pharmacology Pharmaceutics \& Pharmacovigilance | ISSN: 2639-5649

Journal Of Physical Medicine Rehabilitation \& Disabilities | ISSN: 2381-8670

Journal Of Plant Science Current Research | ISSN: 2639-3743

Journal Of Practical \& Professional Nursing | ISSN: 2639-5681

Journal Of Protein Research \& Bioinformatics

Journal Of Psychiatry Depression \& Anxiety | ISSN: 2573-0150

Journal Of Pulmonary Medicine \& Respiratory Research | ISSN: 2573-0177

Journal Of Reproductive Medicine Gynaecology \& Obstetrics | ISSN: 2574-2574

Journal Of Stem Cells Research Development \& Therapy | ISSN: 2381-2060

Journal Of Surgery Current Trends \& Innovations | ISSN: 2578-7284

Journal Of Toxicology Current Research | ISSN: 2639-3735

Journal Of Translational Science And Research

Journal Of Vaccines Research \& Vaccination | ISSN: 2573-0193

Journal Of Virology \& Antivirals

Sports Medicine And Injury Care Journal | ISSN: 2689-8829

Trends In Anatomy \& Physiology | ISSN: 2640-7752

Submit Your Manuscript: https://www.heraldopenaccess.us/submit-manuscript 